\title{
RESPUESTAS EDUCATIVAS AL CAMBIO CLIMÁTICO DESDE EL COLEGIO MADRID: LECCIONES APRENDIDAS Y NUEVOS RETOS RUMBO A CLIMÁNTICA MÉXICO 2021
}

\author{
EDUCATIONAL RESPONSES TO CLIMATE CHANGE FROM COLEGIO MADRID: \\ LESSONS LEARNED AND NEW CHALLENGES TOWARDS CLIMANTICA MEXICO \\ 2021
}

http://dx.doi.org/10.15304/ie.29.6351

Rosa María Catalá

catalarm@gmail.com

\author{
Ana María Jiménez Aparicio \\ anajimenez@colmadrid.edu.mx \\ Ernesto Rico Diener \\ ernestorico@colmadrid.edu.mx \\ Colegio Madrid A.C. (México)
}

\section{RESUMEN}

El Colegio Madrid de la Ciudad de México es un Colegio fundado por el exilio republicano español en el año1941, desde sus orígenes ha sido una institución con una clara vocación ambiental que ha seguido fiel a los principios naturalistas de la Escuela Libre de Enseñanza ${ }^{1}$. Próxima a cumplir ochenta años se mantiene a la vanguardia educativa a través de diversas acciones y participación en proyectos académico-culturales como la que se ha dado en el proyecto Climántica, uno de los de mayor repercusión e impacto en la última década. Paralelamente, el proyecto educativo de la institución evoluciona para responder a las nuevas necesidades de aprendizaje de los estudiantes a través de modelos innovadores de enseñanza, de programas interdisciplinarios y transcurriculares basados en la ética del cuidado y en el trabajo colaborativo. Coyunturalmente, como ciudad y país hemos resentido en los últimos años los efectos del cambio climático a través del incremento de la temperatura anual y la aparición de eventos meteorológicos extremos que nos han llevado a tomar medidas estructurales importantes. En este contexto cotidiano, el trabajo activo de la comunidad es clave para dar respuestas y soluciones a problemas reales a través de la conjugación de las tres dimensiones de la vida escolar: la organizacional, la académica y la cultural. Esta capacidad de adaptación nos está llevando a logros estratégicos basados en el desarrollo del pensamiento crítico, el pensamiento creativo, la comunicación y el ejercicio pleno

Recibido: 17/X/2019. Aceptado: X/2019

1 La Institución Libre de Enseñanza, inspirada por Francisco Giner de los Ríos, fue una de las corrientes pedagógicas que revolucionó la enseñanza entre finales del siglo XIX y principios del XX en España. 
de la ciudadanía de estudiantes y profesores. Un logro destacado reciente ha sido la co-organización con España y Costa Rica del primer campus Climántica Iberoamérica (San José, del 8 al 12 de abril de 2019), con resultados muy alentadores que dan paso ahora al reto de realizar el congreso virtual y campus Climántica México en 2021, en colaboración con la Universidad de Santiago de Compostela y otros socios estratégicos a nivel nacional e internacional, incluyendo a la Universidad de Aveiro, entre otros.

Palabras clave: organización escolar, dimensión cultural, dimensión académica, competencias clave, comunicación, tecnologías para el aprendizaje.

\section{ABSTRACT}

The Colegio Madrid School, located in Mexico City was founded by the republican Spanish exile in 1941. From its origins has shown a clear focus on environmental education, following the naturalist principles of the innovative instructional models that ruled the initial academic programs. It nowadays maintains the same spirit and our school will turn 80 in 2021, responding to new educational demands trough a diversity of actions and projects such as Climántica. This has been one of the most relevant both for its academic and cultural impact in our community in the last decade. At the same time, the academic dimension evolves to respond to the emerging needs in teaching and learning trough the application of innovative models. In this continuous search for better learning environments, the transcurricular approach based on ethics of care and the collaborative work are in sintony with the participation in both national and international projects, such as Climántica. In Mexico City, as citizens of a country that has already felt the serious effects of extreme weather, we are increasingly concerned about taking action at educational, social and infrastructural levels. Along with the scientific facts, we are working in interdisciplinary activities linking social subjects like Mexican history, arts, technology, among others. Additionally, in recent years we have developed an innovative approach to interrelate science and social curricula with the cross curricular citizenship and ethics of care approach, which is showing encouraging results. We have no doubt in recognizing Climántica as the top project that eight years ago started a new era on climate change awareness in our community. Now we face the next challenging action to co-organize Climántica Iberoamérica in México in spring 2021, framed in the $15^{\text {th }}$ and $80^{\text {th }}$ anniversary of Climántica and Colegio Madrid's foundation. It is again proposed to work with our staff of Colegio Madrid, the Universidad de Santiago de Compostela, the Consejería de Educación de la Embajada de España para México y Centroamérica, and other Iberoamerican institutions linked to the Project, including Aveiro's University and other organizations from Costa Rica and regional partners.

Key words: School organization, academic dimension, cultural dimension, core skills, technology, collaborative learning, communication.

\section{INTRODUCCIÓN}

La última década ha sido de grandes cambios educativos a nivel nacional en México, España, en Europa y en el mundo en general. El Colegio Madrid no ha sido la excepción: tuvo y tiene que responder a las múltiples exigencias de un entorno en constante evolución y en donde el cambio climático es uno de los temas que está llevando la delantera en esa transformación educativa, ya que, nos guste o no, estamos frente al mayor reto global que hayamos enfrentado antes como humanidad.

Ante la realidad cotidiana que vivimos desde nuestra experiencia personal cuando observamos y experimentamos continuos cambios meteorológicos, o desde el continuo caudal de información que recibimos a través de los diversos medios tradicionales y electrónicos, las sociedades y en 
particular la gente joven está finalmente tomando acción y anticipándose a las instituciones: es para ellos un hecho que ni los gobiernos ni los distintos sectores económicos (particularmente el energético) han estado a la altura para atender la compleja realidad ambiental, social y económica que implica seguir viviendo de manera sostenible en la Tierra.

Todo parece indicar que al menos la escuela y los sectores educativos han sido más sensibles que los gobernantes y tras décadas de programas de educación ambiental y de convivencia profesional con expertos de universidades y centros de investigación, finalmente se está logrando ver un fenómeno de transformación alentador en muchos de nuestros jóvenes y niños: están pidiendo imperativamente y con buenas bases argumentativas la necesidad de un cambio de rumbo urgente. Creemos que en esta nueva realidad las respuestas institucionales basadas en una reorganización estructural y estratégica de muchas instituciones educativas del mundo durante la última década han logrado desarrollar una conciencia ambiental y social colectiva entre sus comunidades que los prepara más que para la erudición, a diseñar, construir y encontrar soluciones a problemas complejos. En el Colegio Madrid llevábamos ventaja, no tuvimos que emprender cambios en enfoque ya que nuestro paradigma siempre fue el de formar personas ética y ambientalmente responsables. Sin duda un gran avance desde el que basamos el siguiente paso: actualizarnos e innovamos en la búsqueda de modelos de enseñanza y evaluación de los alumnos. En esta evolución estamos convencidos que la participación continua en proyectos juveniles como Climántica han sido piezas claves en la motivación participativa de maestros y alumnos de nuestro Colegio. Como cabe esperar, ha sido, sin embargo, la combinación de esfuerzos a diferentes niveles y dimensiones los que en su conjunto han llevado a los resultados alentadores que se tienen actualmente y que nos llevan a continuar en la dirección trazada la última década a nivel de organización escolar. Esbozaremos brevemente las que consideramos más importantes.

\section{Antecedentes: la educación ambiental antes de Climántica en el CM}

En México, como en muchos países de la región iberoamericana, la educación ambiental ha sido desde hace más de cuatro décadas el patito feo de los currículos escolares. La introducción forzada de temáticas como la contaminación o el cuidado de los ecosistemas se ha hecho siempre de manera indirecta y descontextualizada. Dichos conceptos se abordan desde los programas de Ciencias Naturales en preescolar y primaria y más adelante, verticalmente se incluyen en los currículos de Biología y Química. ${ }^{2}$ Más recientemente y a raíz de las problemáticas sociales asociadas a la problemática ambiental, algunas asignaturas del área social, como la educación cívica, comenzaron también a considerar el tema ambiental en sus programas. Fueron años de poca repercusión y mínimo impacto en las conductas de los alumnos en las escuelas y más tarde de los adultos en su vida cívica y profesional.

En nuestro Colegio, sin embargo, desde siempre, pero principalmente a partir de la década de los 90, se llevaron a cabo diversos proyectos tanto escolares como estudiantiles que han buscado ampliar esta limitada visión y procurar la participación activa de nuestra de nuestra comunidad para

2 Los programas de educación ambiental en México. http://dgeiawf.semarnat.gob.mx, consultada el 14 de octubre de 2019. 
resolver los crecientes problemas de una ciudad tan grande y complicada como es la Ciudad de México $^{3}$. Se ha cobrado conciencia que la acción tenía que ser local y la suma de ellas tendría un impacto global y empezamos a desarrollar importantes programas como la separación de residuos en recipientes diferenciados. A tal grado fuimos pioneros, que no encontrábamos proveedores y tuvimos que diseñar nuestro propio sistema. Los primeros proyectos autogestivos de alumnos en favor del medio ambiente (Comité estudiantil del medio ambiente del Colegio Madrid) surgieron a la luz del foro mundial del agua realizado en 2006 en el entonces Distrito Federal. También empezaron los acopios de materiales útiles para su reciclaje o reúso y a nivel administrativo institucional nos abocamos a la enorme tarea de transformar la gestión de la energía, el agua y la basura, el consumo responsable y ser congruentes con los mensajes educativos hacia los alumnos. De estas acciones destacan el cambio progresivo (y ahora completo) de lámparas y luminarias por equipos de menor consumo, la reparación de tuberías rotas y de fugas en toda la instalación, la venta o disposición adecuada de residuos con la debida separación de basura, el uso de productos y materiales de limpieza ecológicos, entre otros. Debido a que somos una comunidad grande con aproximadamente 1600 alumnos y 400 empleados, los costos de inversión para todo ello fueron significativos, pero también los ahorros consecuentes han mejorado en gran medida las eficiencias administrativas.

\section{La década 2012-2019. La llegada de Climántica y vientos de cambio}

Como ya se refirió con anterioridad, paralelamente a la llegada del proyecto Climántica al Colegio (gracias a que nos pusiera en contacto el Dr. Andoni Garritz, ex director de la Facultad de Química de la UNAM y quien fuera también un destacado miembro del Consejo escolar) ${ }^{4}$, el Colegio había emprendido importantes acciones y programas destinados a reforzar tanto los conocimientos de los alumnos sobre temas ambientales en las aulas como su participación consciente y autónoma en la construcción de un entorno escolar, familiar y social más acorde con las necesidades de conservación y cuidado.

Con la adopción de Climántica como modelo de proyecto intercultural se abrió una nueva forma de interacción de nuestros alumnos y maestros con la problemática ambiental: abierta y claramente enfocada al cambio climático, una realidad a la que desde finales de los noventa veníamos siendo alertados, pero rodeada siempre de un marcado desconocimiento de sus implicaciones. El problema actual se veía entonces todavía lejos y si bien la temática se estaba incluyendo en los programas de estudio, la perspectiva era poco realista y reduccionista del problema. La primera generación de alumnos y maestros que participó en el congreso virtual y en el campo de Campus do Mar, en Vigo y Santiago de Compostela en 2012 regresó con una visión completamente distinta: no sólo sabíamos poco, estábamos haciendo también muy poco para generar la conciencia colectiva del problema a nivel escolar y de la comunidad. La idea gustó y se propagó rápidamente entre profesores y alumnos de la secundaria del Colegio.

3 La Educación Ambiental en el Colegio Madrid. Transatlántica de Educación, México, 2012. https://sede. educacion.gob.es/publiventa/transatlantica-de-educacion-n-18-la-educacion-un-derecho-que-abre-lapuerta-a-otros-derechos/ensenanza-lengua-espanola/22187

4 Proyecto Climántica, Educación Química, 2011.http://revistas.unam.mx/index.php/req/article/view/64461/56590 
Desde entonces la cantidad de alumnos que han participado ininterrumpidamente ha ido creciendo en número y calidad de los trabajos enviados.

Las autoridades académicas y administrativas de Climántica en la Universidad de Santiago de Compostela y las del Colegio Madrid empezamos a estrechar lazos como pocas veces se había logrado a nivel interinstitucional. Adicionalmente, el hecho de que el Colegio sea un Centro de Convenio en el Extranjero nos convierte en una institución mexicano-española que recibe apoyos de formación académica y de contactos logísticos de la Consejería de Educación de la Embajada de España en México, una situación idónea para establecer colaboraciones con un país y continente íntimamente ligados a la historia del Colegio. Una nueva era intercultural, psicosocialmente responsable y ligada a nuevas metodologías de enseñanza para el desarrollo del pensamiento crítico y creativo, iniciaron coincidentemente con la llegada de Climántica, un proyecto que desde el inicio fue totalmente acorde y coherente con las aspiraciones institucionales del Colegio.

A lo largo de estos años, la alerta ambiental se ha disparado a todos los niveles en el Colegio: institucional, estudiantil y docente. Paralelamente en México y en otros países de la región iberoamericana esta problemática se suma a otros fenómenos sociales agudos y característicos de economías emergentes como la nuestra: consumimos mucho y nuestra producción se reduce a la extracción de materias primas: petróleo y minería principalmente. Problemáticas ligadas a la pobreza propia de nuestros modelos sociopolíticos, a las migraciones imparables y al desequilibrio económico y energético entre el norte y sur. Una brecha que todavía se percibe insalvable entre las sociedades industrializadas, por lo que dependemos íntimamente de los recursos y apoyos internacionales para sobrellevar con muchas dificultades nuestra forma de vida.

En estos años Climántica y otros proyectos científico-sociales y culturales del Colegio fueron elementos disparadores de otras iniciativas que han entrado transcurricularmente de lleno a formar parte de nuestras acciones para dar respuestas adecuadas a las necesidades actuales de formación del alumnado. La organización académica y procedimental, así como su estructura organizacional los hicieron idóneos para ayudar a construir y encajar de forma congruente y natural a tres programas estratégicos permanentes e interconectados del Colegio. Si bien, no todos son nuevos en sus objetivos y acciones, estos programas se han redefinido y otorgado un andamiaje innovador al proyecto académico ${ }^{5}$ a partir a la comprensión y atención de problemáticas emergentes de la población estudiantil y de la sociedad en general. Se describen brevemente a continuación:

- Madrid Sostenible: destinado a integrar el conjunto de acciones académicas, culturales e institucionales de toda la comunidad para la formación de futuros ciudadanos capaces de construir entornos de vida sustentados en la relación armónica y en equilibrio con la naturaleza.

- Madrid Contigo: programa encargado del cuidado y bienestar físico y psicosocial de todos los miembros de la comunidad. La vía incluyente que hemos optado como base de

5 El proyecto educativo del Colegio Madrid. Boletín electrónico Nosotros Ahora junio 2018 https:// colegiomadrid.edu.mx/archivos/NosotrosAhora/NosAhora1314.pdf 
la buena convivencia, congruente con los preceptos de una cultura de paz, apoyado en el autocuidado, en el diálogo y la búsqueda de acuerdos para resolver conflictos y actuar efectivamente en situaciones de riesgo.

- Madrid Intercultural: integrado para atender las necesidades de comunicación e interrelación estudiantil de manera creativa y propositiva a través del enfoque comunicativo en la enseñanza de otras lenguas y de la vinculación interinstitucional para la movilidad y el intercambio de experiencias de aprendizaje.

En la instrumentación de estas respuestas a los cambios generacionales y a las problemáticas descritas no han sido pocos los momentos difíciles, la falta de claridad en los primeros documentos, la falta de recursos y de tiempos siempre más cortos de lo necesario. Son afortunadamente también muchas las señales de avance que nos alientan a seguir adelante en su implementación y crecimiento como se ve en algunos puntos a continuación.

\section{Un estudio de caso pertinente: los eventos hidrometeorológicos del año 2017 como contexto de aprendizaje}

El año 2017 fue particularmente difícil para el Colegio Madrid, de mayo a septiembre vivimos dos de los eventos que más han sacudido a nuestra comunidad. El 29 de mayo y 6 de septiembre primero, con dos fenómenos torrenciales de dimensiones extraordinarias, y un terremoto después, (sobre el que la comunidad Climántica conoce muy bien) el 19 de septiembre, sucedieron exactamente en la zona donde está ubicado el Colegio. Sin entrar en mayores detalles, historias de vida institucional que afortunadamente no tuvieron víctimas que lamentar, las instalaciones del Colegio, ya de por si erosionadas por las lluvias, se vieron también afectadas por el terremoto. Cinco edificios (de un total de 22) quedaron seriamente dañados por los embates de la naturaleza. No podemos achacar todo al cambio climático, lo cierto es que las dos tormentas seguidas por lluvias copiosas fueron de una dimensión escalofriante, como si un pequeño y focalizado huracán nos hubiera pasado por encima; fueron totalmente fuera de lo normal. En ambas ocasiones el Colegio tuvo una respuesta ejemplar y sabemos que es por algo sumamente importante ligado al cuidado de la comunidad: estamos siempre preparados. Estar preparado significa conocer, planear y ejecutar planes de emergencia con pasos muy claros y simples que todos podemos realizar en pocos minutos para ponernos a salvo. Es un momento en el que los programas Madrid Sustentable y Madrid Contigo se dieron claramente la mano en nuestra comunidad.

\section{Las lecciones y sus aprendizajes: Tláloc, dios de la lluvia en el Colegio Madrid}

Transcurridos ocho meses y tras la rápida actuación de las autoridades para reparar los daños, asistimos a la inauguración de una obra sin precedentes: la construcción de una cisterna de captación pluvial con un aforo mayor a medio millón de decímetros cúbicos $(\mathrm{L})$. ¿Era realmente necesaria esa inversión para una obra monumental subterránea que ni siquiera se ve? Los hechos y los datos con los que contábamos claramente demuestran que sí, y para que se pudiera aprovechar esa información como contexto de aprendizaje de nuestros alumnos de manera interdisciplinaria, elaboramos dos 
materiales muy valiosos. Por un lado, en el patio de la primaria (históricamente la parte más baja del terreno del Colegio y por tanto la que siempre se inundaba hasta 2018) se colocó un cartel de gran tamaño titulado "Tláloc en el Colegio Madrid, Magnánimo y Temible”, en el que de manera didáctica y muy gráfica se mostró a los niños y a la comunidad asistente un relato histórico de lo que significa la lluvia para los habitantes del valle de México y de su poder ambivalente como dadora y destructora de vida. Cabe destacar que en el Colegio existe una estación de medición de precipitación pluvial (disdrómetro) que forma parte de la red de monitoreo del Instituto de Ingeniería de la UNAM, por lo que pudimos conocer en tiempo real la cantidad de agua que cayó sobre el Colegio los días en que se dieron los hechos.

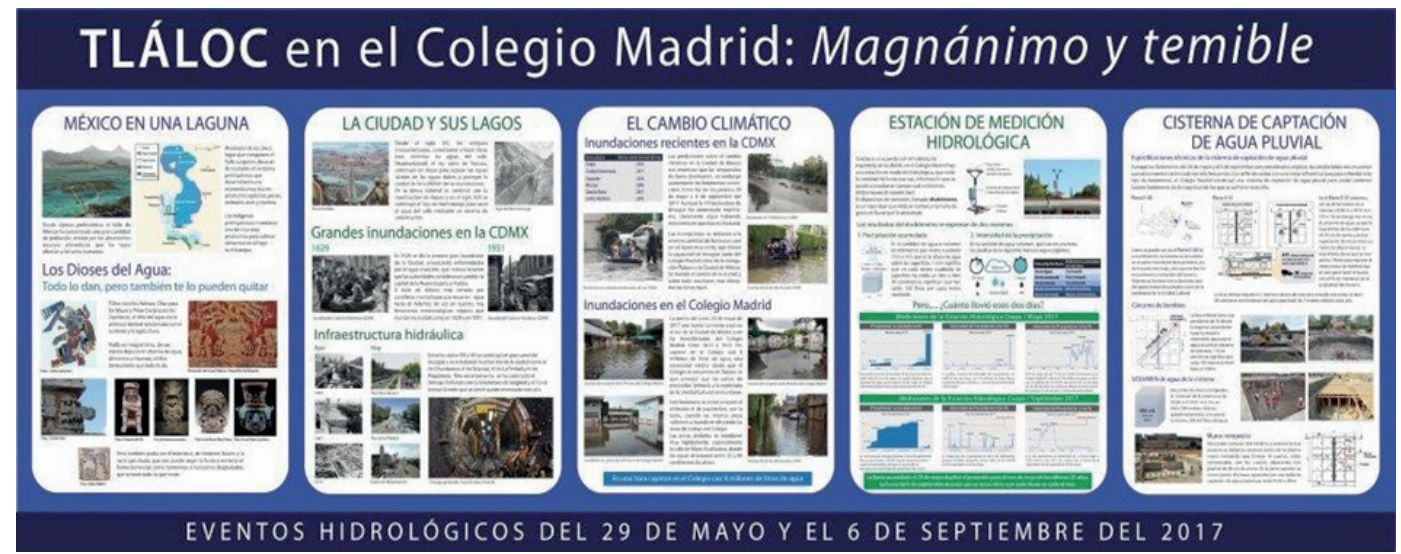

Figura 1. Cartel con el relato cronológico que vincula de manera interdisciplinaria las inundaciones sufridas en el Colegio Madrid en el año 2017 con diversas asignaturas para su uso didáctico.

Por otro lado, y para los profesores y alumnos mayores de secundaria y bachillerato, se elaboró un material didáctico en formato de presentación electrónica con un cúmulo importante y muy interesante de información útil para generar secuencias didácticas interdisciplinarias, a disposición de los profesores que desean aprovecharlo como contexto ambiental en la enseñanza de asignaturas vinculadas a estos fenómenos.

Esta información ha sido desde entonces aprovechada por maestras y profesores del Colegio como contexto de aprendizaje en temas ambientales, nada más cercano que lo que nos ocurrió a nosotros mismos para comprender los efectos de fenómenos que pueden cambiar en minutos el curso de un ciclo escolar y de la vida de muchas personas. Porque si bien no hubo pérdidas personales, varias familias de alumnos y trabajadores vecinos al Colegio si tuvieron importantes daños patrimoniales durante las inundaciones. En las figuras anexas se incluyen imágenes de los dos materiales iniciando por el cartel que se encuentra en la sección primaria. En ambos se presentan datos hidrológicos de la cuenca de México (vinculación con geografía), la importancia de los lagos del valle de México en la configuración de las civilizaciones mesoamericanas (historia), el funcionamiento de la estación de medición hidrológica (física, matemáticas), los efectos del cambio 
climático en nuestro país (educación ambiental) y por último la construcción de la cisterna, con sus consideraciones útiles para los alumnos mayores orientados al área de diseño y arquitectura
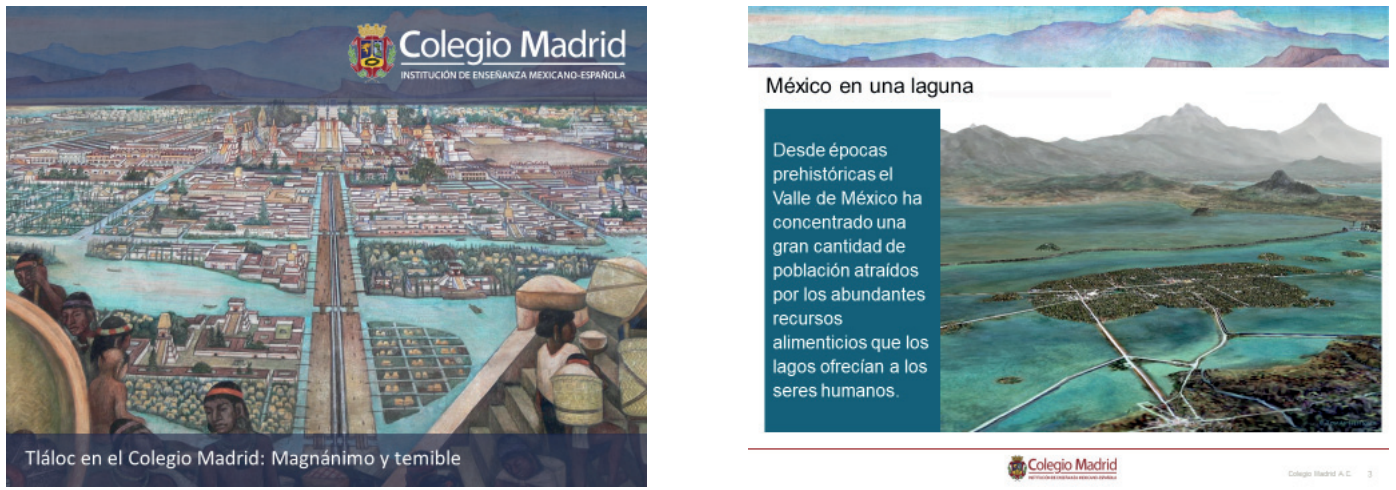

Figuras 2-3. Imágenes de la presentación electrónica "Tláloc en el Colegio Madrid" dirigido a profesores y alumnos de secundaria y bachillerato.

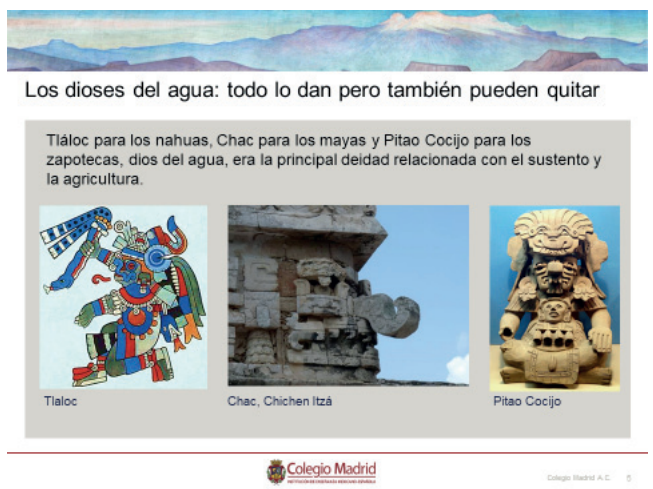

Figura 4. Tialoc, Chac, Pitao Cocijo: los dioses del agua en las culturas mesoamericanas.

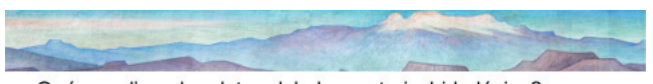

¿Qué nos dicen los datos del observatorio hidrológico?

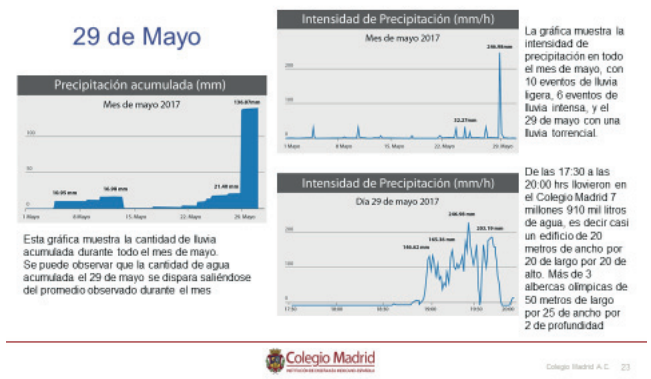

Figura 6. Datos del observatorio hidrológico.

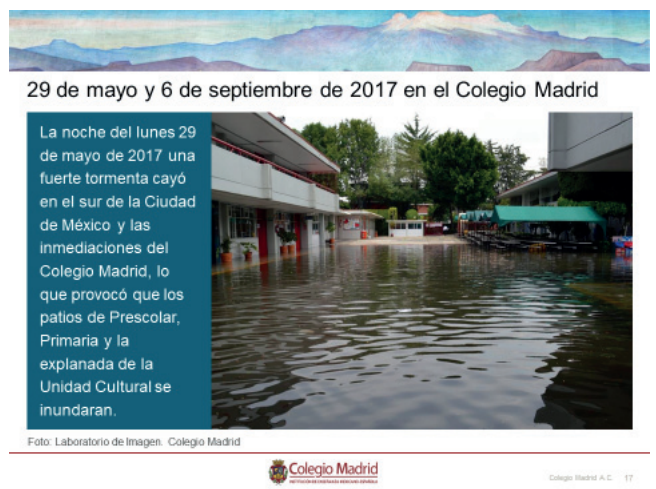

Figura 5. Tormenta en las inmediaciones del Colegio Madrid.

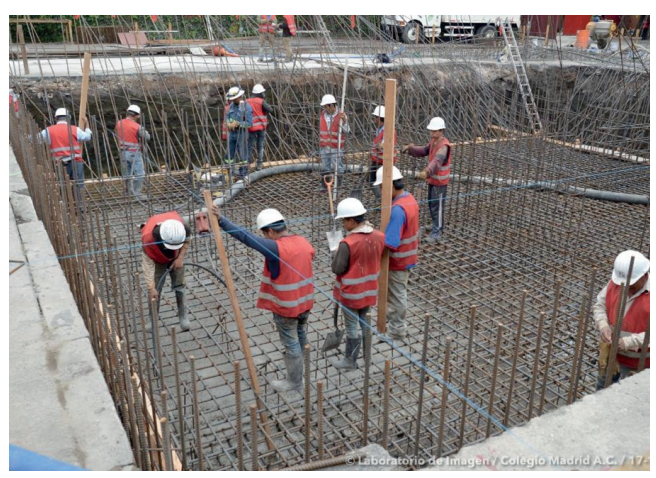

Figura 7. 


\section{Figura 8.}

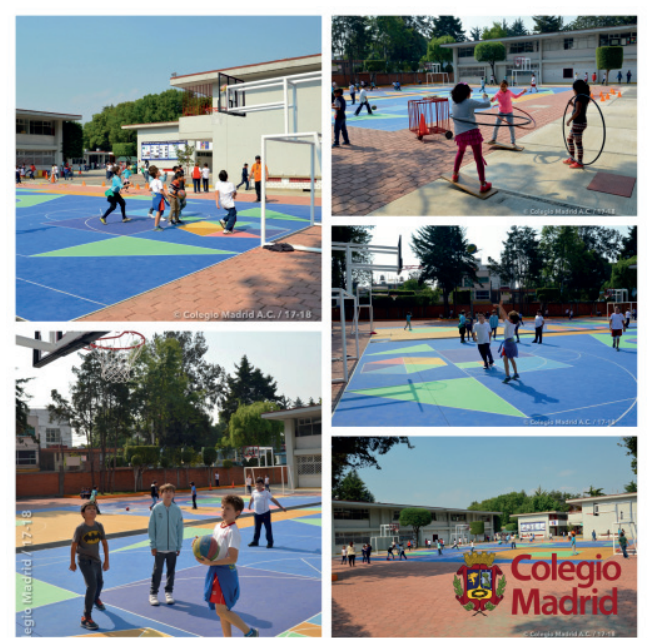

Figuras 7 y 8. Vista de las fases finales de construcción de la cisterna de captación pluvial y vista actual de la parte superior de la misma, ubicada en el patio de juegos de la sección primaria.

La cisterna ya ha probado su funcionamiento oportuno y eficientemente, evitando inundaciones por eventos semejantes a los acontecidos en 2017. Este año 2019, contrariamente a lo sucedido en los dos anteriores, está siendo un año de poca agua y sequía, por lo que el tema de cambio climático volverá a aparecer en nuestras aulas pero en otro contexto: el de la escasez y sus temibles consecuencias en grandes extensiones del país. Al momento de escribir este artículo otros grandes desastres naturales están sucediendo, el huracán Dorian de una enorme fuerza destructiva se ha ensañado con las Bahamas y el tifón Hagibis, que ha dejado un caudal de daños en Japón, se han cobrado vidas de personas que no pudieron ponerse a resguardo. De tal calado es y seguirá siendo el reto que enfrentamos. Unos por falta y otros por exceso, todos en el mundo estamos ligados a la ambivalencia de los dioses del agua, un aprendizaje que no pasará desapercibido nunca más por nuestros estudiantes.

\section{Otro indicador de avance: Climántica lberoamérica 2019 en Costa Rica}

Como un ejemplo de lo que puede lograrse a nivel de cooperación internacional e interinstitucional alrededor de la acción educativa para la enseñanza de temas asociados a los Objetivos del Desarrollo Sostenible (ODS) de la agenda 2030, logramos coorganizar entre tres países distantes el campus Climántica Iberoamérica en San José de Costa Rica, del 8 al 12 de abril de 2019. La idea primero y luego la tarea de traer un campus internacional Climántica al continente americano resultó un reto complejo, pero sumamente satisfactorio a la postre para todos. Se necesitó de gran apoyo institucional de organizaciones de tres países: España, Costa Rica y México para lograrlo y se tuvo la participación de último momento de otro país vecino de la región: Perú, que asistió representado por dos profesoras y 10 alumnos limeños. Terminadas las gestiones, que tomaron 
más de ocho meses de trabajo y un viaje de avanzada por parte de los co- organizadores de España y México, alcanzamos una cifra importante de 77 alumnos participantes.

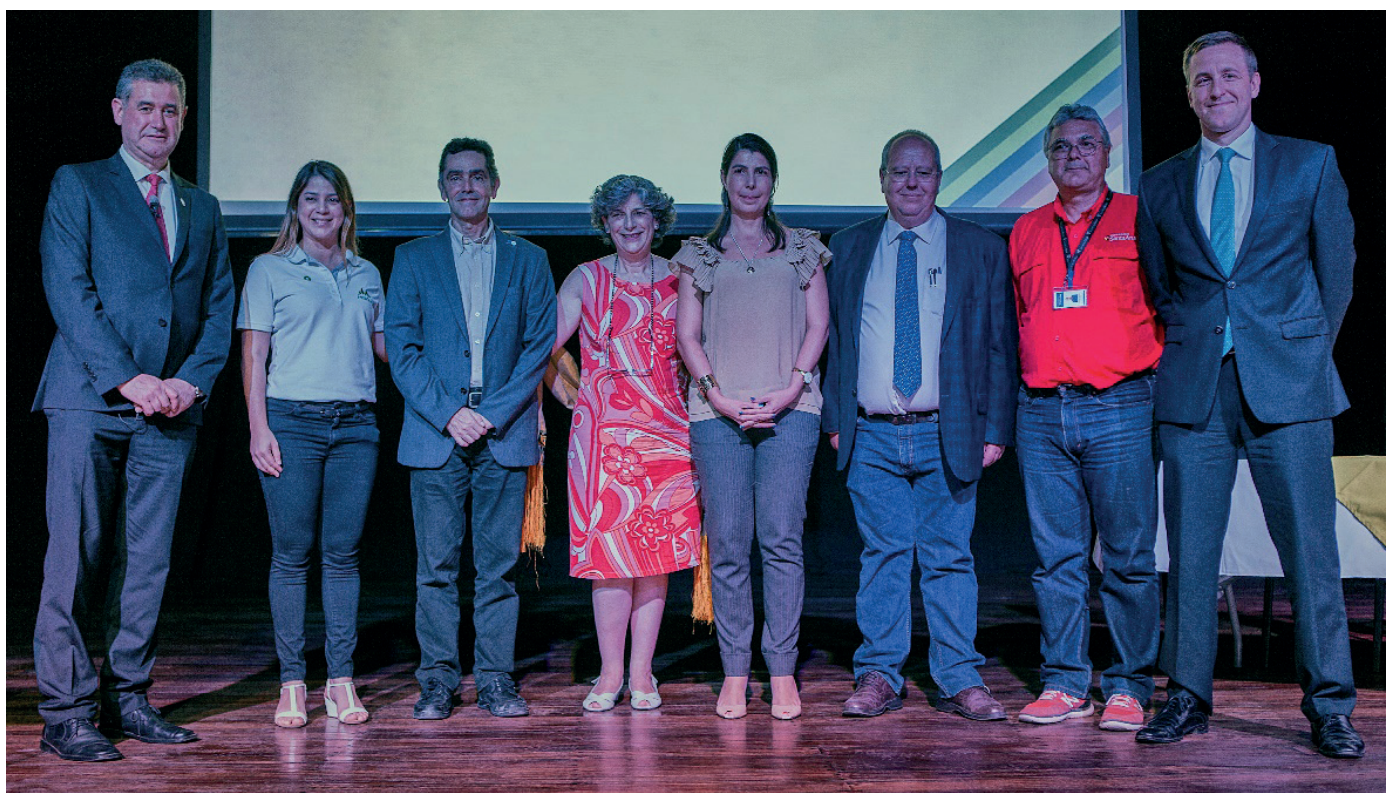

Figura 9. Personalidades representantes de Climántica, Colegio Madrid y Misión $2^{\circ}$ en la inauguración del Campus Climántica Iberoamérica 2019. Destaca la presencia del delegado de la UNESCO para Costa Rica y del Cónsul General de España en el país anfitrión.

La de Galicia fue por mucho la delegación más grande con alumnos de varios institutos de La Coruña y de Lugo. La del Colegio Madrid se integró con 20 alumnos, la mayor que hemos enviado a un evento Climántica. En esta ocasión coincidieron estudiantes de secundaria y bachillerato, algo que resultó atractivo y enriquecedor tanto para los jóvenes como para sus maestros y monitores. Cabe destacar que la totalidad del campus estudiantil estuvo a cargo de talleristas gallegos y españoles ex asistentes a Climántica, proyecto que en 2021 cumplirá sus primeros 15 años de trabajo ininterrumpido.

Esperamos que al pasar de los años y con la suma de más participantes del Colegio, alguno de ellos se incorpore también al equipo de jóvenes adultos responsables, sin duda ellos logran mover anímica, académica y artísticamente a todos los equipos, por lo que podemos decir sin temor a equivocarnos que son el verdadero motor del campus. 


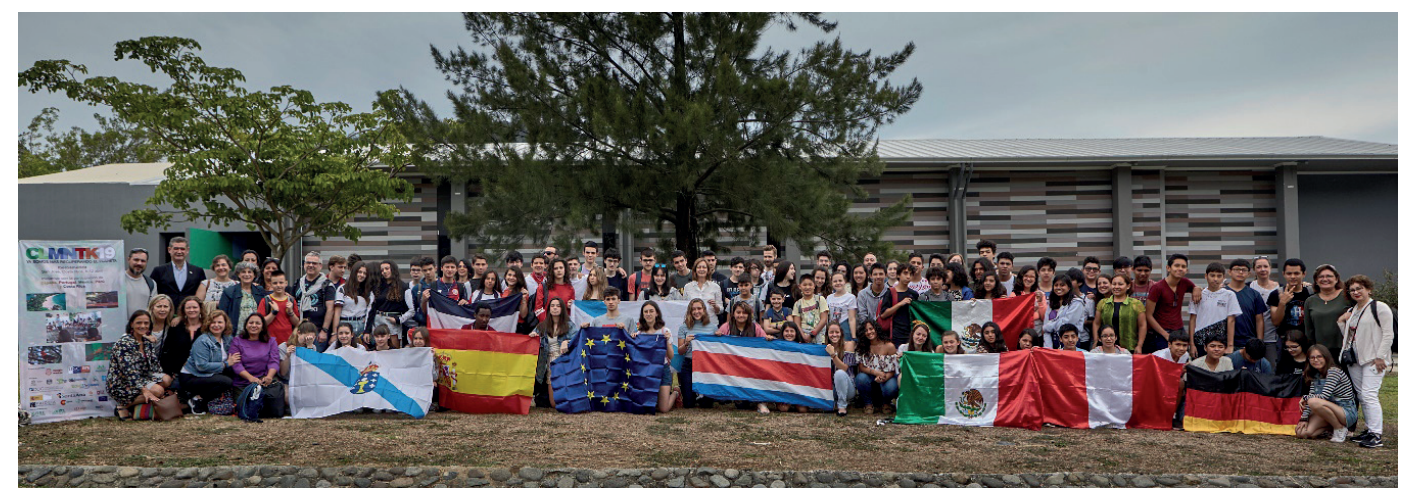

Figura 10. Las delegaciones de alumnos, profesores y organizadores de cuatro países iberoamericanos: GaliciaEspaña, México, Perú y Costa Rica, país anfitrión.

Gracias a numerosos factores humanos, pero también a las excelentes instalaciones y recursos, los aprendizajes y el derroche de talento estudiantil fueron contagiosos desde el primer día. Los estudiantes iniciaron su intensas capacitaciones y clases teórico-prácticas enmarcados en el claro desarrollo del pensamiento crítico, la comunicación efectiva y el pensamiento creativo que desde el segundo día ya se apoderó de todo el campus. El resultado, oportunamente documentado por los responsables del proyecto Climántica desde su página web puede consultarse en la siguiente liga: https:/www.facebook.com/climanticaoficial/videos/611864235948232/?epa=SEARCH_BO
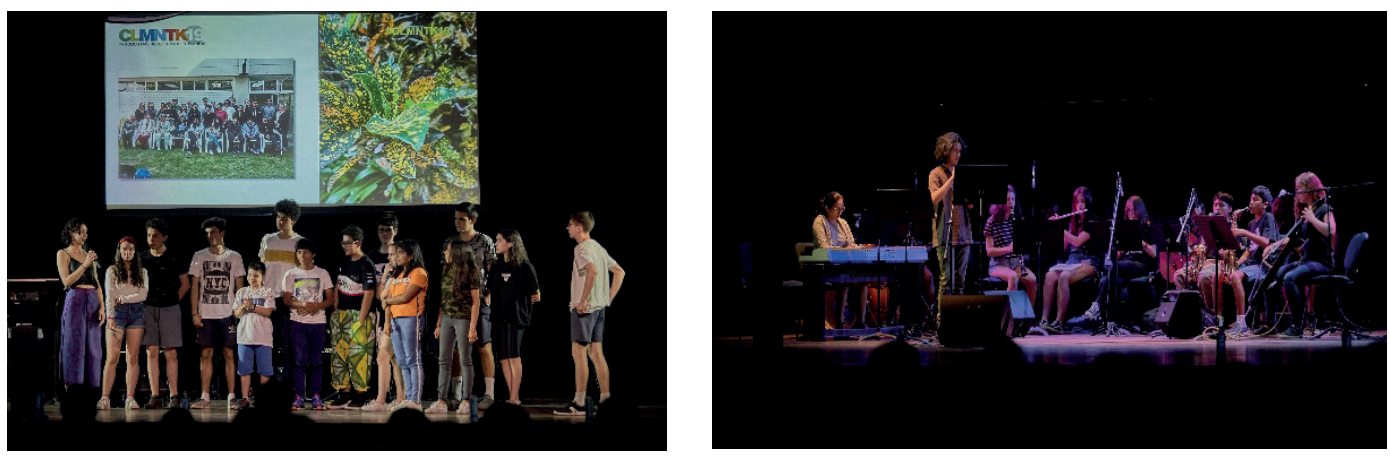

Figura 11. Escenas durante la preparación de la presentación final. El papel de los monitores es clave para el desarrollo de las actividades estudiantiles durante el campus.

\section{¿Cuál fue nuestro principal papel como parte del equipo organizador?}

Después de participar por más de siete años en los congresos virtuales y los campus europeos de Climántica, pensábamos que teníamos mucho camino recorrido en la nueva tarea como organizadores, pero hoy sabemos que no es así. La logística tuvo que hacerse desde países que no éramos sede y la cantidad de participantes obligó a buscar apoyos tanto voluntarios como contratados 
para asegurar alojamiento, alimentación, transporte y actividades recreativas y culturales para todo el gran grupo.

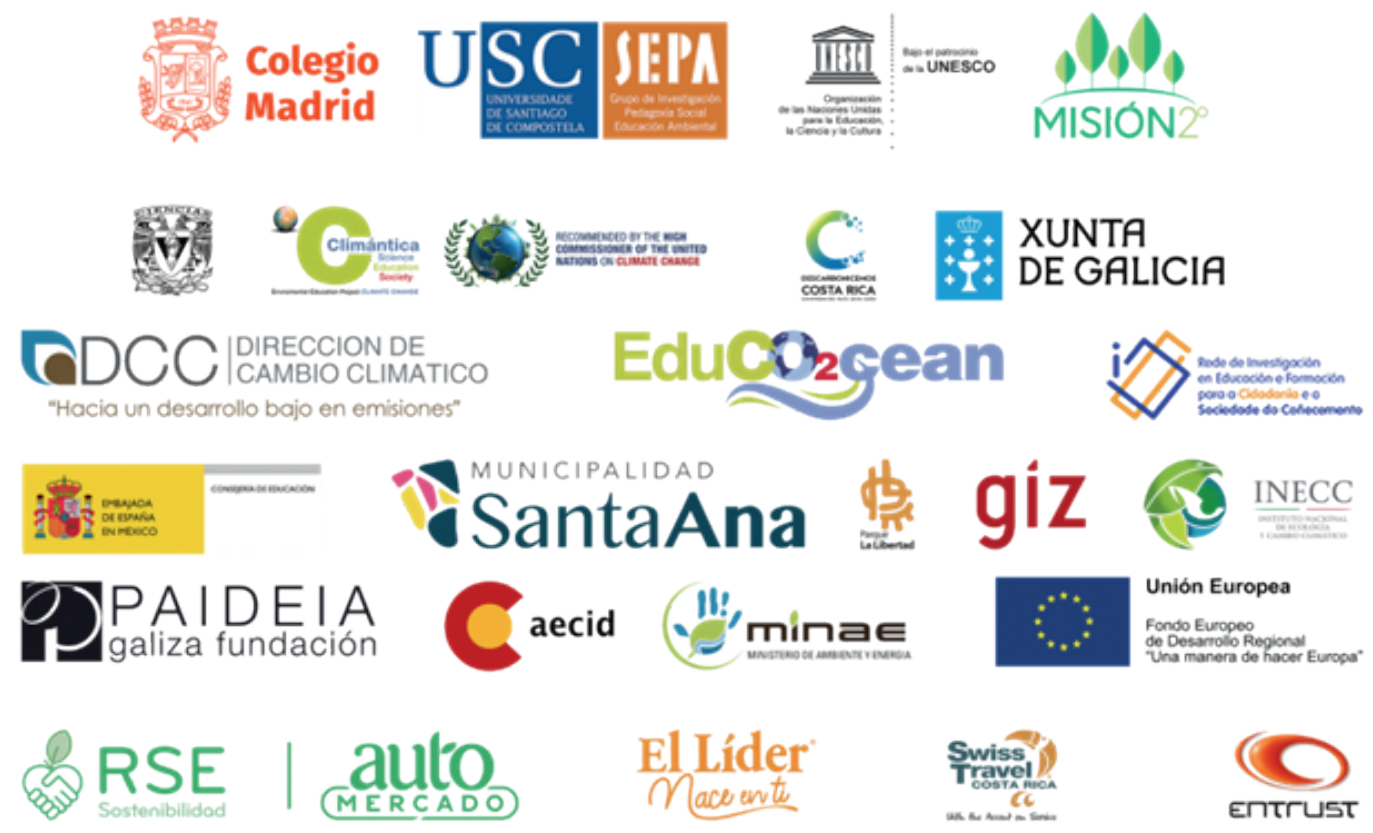

Figura 12. Logotipos de todas las organizaciones, instituciones y empresas involucradas en la organización y realización del campus Climántica Costa Rica 2019. En las primeras filas aparecen las instituciones organizadoras y la UNESCO como aval y patrocinador de la delegación española. Los patrocinadores costarricenses jugaron un papel importante al facilitar recursos para el bienestar de todos los asistentes al evento.

Los que han realizado este tipo de actividades como una actividad extraescolar de sus centros saben que además hay que tomar en cuenta factores como servicios de salud, seguridad y una larga lista adicional de necesidades que deben estar cubiertas y garantizadas que den confianza y tranquilidad tanto a los viajeros como a sus familias. En este esfuerzo, tanto el Colegio Madrid como nuestro par, la ONG Misión $2^{\circ}$, en más de una ocasión tuvimos que mediar para que se comprendiera la idiosincrasia - tan distinta a la europea - de nuestras culturas y creo que lo hicimos bien, ya que los chicos españoles y sus profesores muy pronto se hallaron cómodos y contentos de este lado del Atlántico. Tal vez esperaban más sol en San José, donde en varios momentos fuimos sorprendidos por lluvias en plena primavera. Una tarde, la rápida tormenta remató el buen ambiente con un magnífico arco iris que nos hizo salir a todos de los espacios de trabajo para tomarnos la impresionante foto del recuerdo. En las figuras siguientes pueden verse imágenes de las instalaciones donde nos alojamos a lo largo del campus en San José, un lugar cálido donde a pesar de algunas incomodidades de espacio, siempre estuvimos a gusto y bien atendidos. 

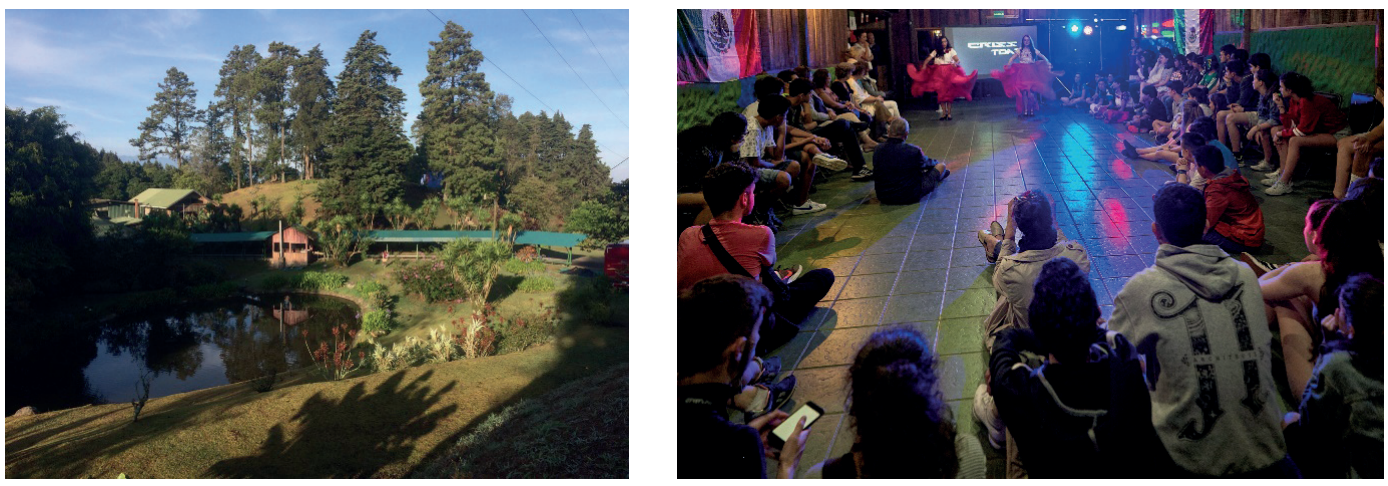

Figura 13.

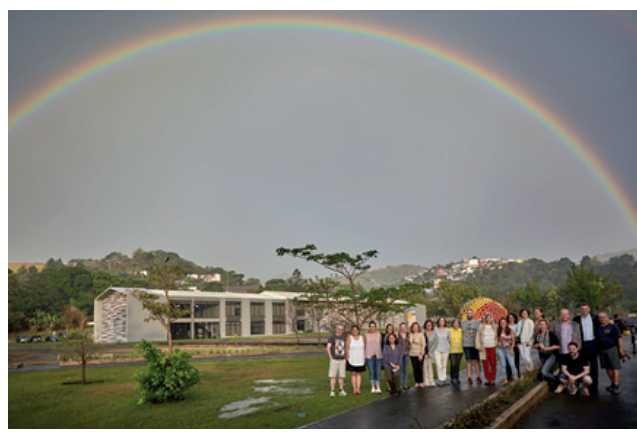

Figura 14.

Figuras 13 y 14. Imágenes de las instalaciones y de algunas actividades recreativas en el campus Climántica Costa Rica 2019. El Parque La Libertad fue el espacio idóneo para realizar las actividades académicas y artísticas de los participantes.

\section{Un seminario docente de gran calidad}

Finalmente queremos destacar que uno de los esfuerzos más importantes que aportó nuestro Colegio Madrid fue la organización completa de un Seminario Docente centrado en compartir experiencias de investigación-acción sobre educación ambiental y temas vinculados al cambio climático. No hay duda alguna de que los 22 profesores nos llevamos de regreso a nuestros centros educativos valiosas experiencias para seguir creciendo en este esfuerzo. Adicionalmente, y en ello va un valor agregado importante, las redes que se generan anualmente abren importantes oportunidades a nuestros profesores, quienes han encontrado un espacio relevante de crecimiento profesional alrededor del proyecto y de trabajo colaborativo internacional, tanto virtual como presencial. En el Seminario participaron expertos universitarios de tres países, organizaciones de la sociedad civil, autoridades municipales, profesores, monitores y alumnos. Tuvimos la capacidad de convocar a expertos de tres universidades: USC de Galicia, UNAM de México y Universidad Nacional de 
Costa Rica. Por otro lado, en el terreno institucional asistieron representantes del INECC (Instituto Nacional de Ecología y Cambio Climático) organismo descentralizado de México, la directora del Parque La Libertad, un proyecto de inserción social auspiciado en conjunto por capital público y privado de Costa Rica, y también de la valiosas aportaciones de la ONG Misión $2^{\circ}$ cuya trabajo se centra en ayudar a estudiantes de diversas escuelas costarricenses para organizarse y participar activamente en iniciativas ambientales, tanto dentro como fuera del país vecino.
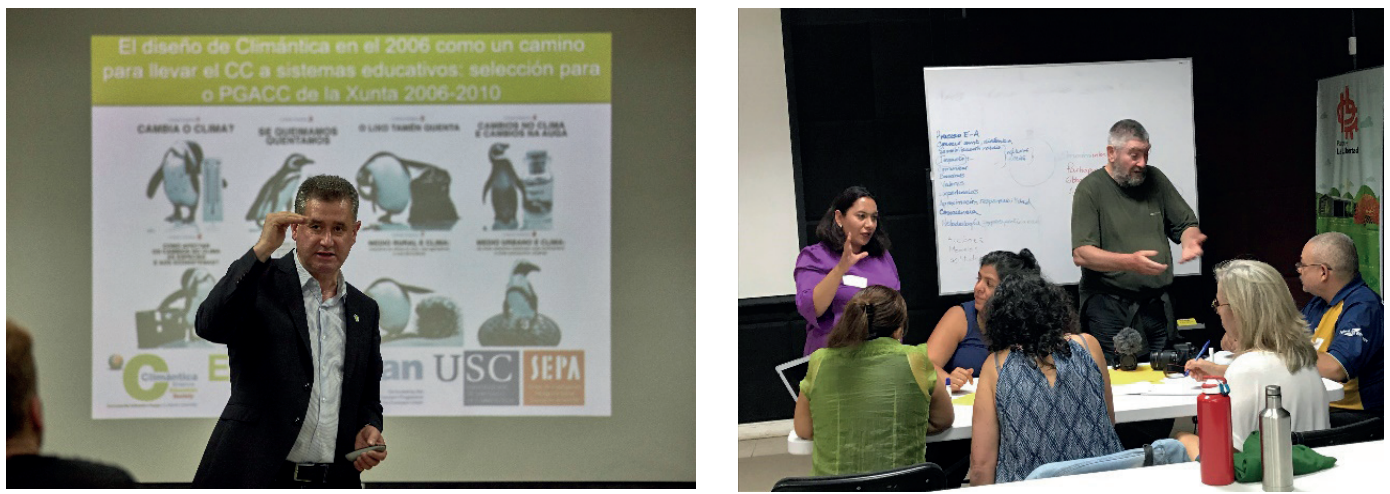

Figuras 15 y 16. Escenas durante el seminario docente paralelo al campus estudiantil.

\section{Nuevos tiempos, nuevos retos rumbo a Climántica Iberoamérica-México 2021}

El camino se hace andando y este parece que será largo y productivo. Acabado el campus de Costa Rica hablamos de una siguiente sede para alojar la versión iberoamericana; entonces no teníamos claro quiénes recogerían el guante ni cuándo sería la próxima reunión de este lado del planeta. Pero hace unas pocas semanas recibimos desde Galicia una llamada que nos llenó de orgullo y nerviosismo al mismo tiempo: en la USC piensan que están listos... ¿se animan a organizarlo en México para 2021? Enseguida dijimos que sí; hay motivos importantes para hacerlo. En esa primavera Climántica cumplirá 15 años de iniciar el proyecto y un par de meses más tarde, el 21 de junio, el Colegio Madrid celebrará el 80 aniversario de su fundación. Una organización joven y otra ya madura que a pesar de la distancia y sus propósitos, tienen mucho más en común de lo que pensaron al principio. Juntas volveremos a planear, a organizar y a buscar los recursos para hacer posible otra cita, ahora en nuestro país.

Por un lado será más fácil para nosotros, pero al ser México mucho más grande, complejo y diverso, tendrán que ser muchas más las puertas que habrá que tocar, empezaremos muy pronto para hacerlo posible. En los próximos meses volveremos a medir nuestras fuerzas y confirmar que en educación todo se ha escrito y al mismo tiempo todo sigue sin escribirse. Por allí hay que empezar. Poniendo en blanco y negro lo que se quiere, identificando lo que ya se tiene y buscando lo que falta para seguir escribiendo una gran historia de entendimiento y cooperación.

Finalmente, la apertura y reconocimiento deben extenderse también a otros colegios e instituciones de educación de México e Iberoamérica. Pensamos que la mejor manera no es solamente 
a través de lo que ya sabemos, sino completar los recursos educativos del proyecto iberoamericano con materiales didácticos propios, la impartición de talleres presenciales y actividades en línea desde una plataforma electrónica que permita descargar los recursos. En eso, instituciones mexicanas como CONABIO y el propio INECC pueden ser por lo pronto de gran ayuda. Recomendamos particularmente la consulta de la página "El cambio Climático de frente", con información actualizada sobre el tema en forma de tablas, infografías y otros recursos.
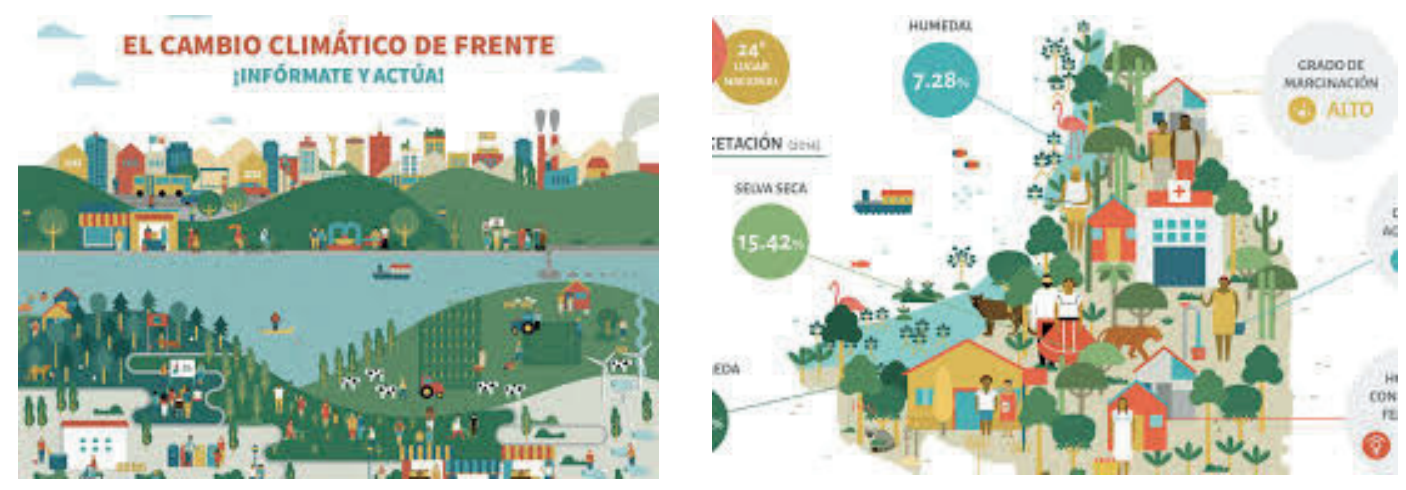

Figura 17. Imágenes de pantalla de la plataforma "El Cambio Climático de Frente", material educativo en línea generado por el INECC (Instituto Nacional de Ecología y Cambio Climático, de México.

\section{A modo de conclusión}

Estamos viviendo un momento histórico irrepetible en donde estudiantes de todo el mundo se están levantando para defender su derecho a detener los efectos devastadores derivados del hedonismo energético del mal llamado "primer mundo". Esas visiones egoístas y hasta negadoras de los impactos del cambio climático están quedándose sin argumentos y la participación de la sociedad civil cuenta más que nunca con herramientas de comunicación para hacer llegar sus premisas y exigencias a miles de destinos de los cinco continentes. Las nuevas generaciones saben que la responsabilidad es compartida y que si bien hay que exigir a los demás, es necesario también cumplir a nivel personal y comunitariamente con tres reglas básicas para favorecer un regreso al equilibrio ecológico. 1.-Dejar en lo posible de quemar combustibles fósiles para ir de un lugar a otro (léase caminar cuando se pueda), 2.-Participar en campañas de reforestación y 3.-Reducir el consumo y uso de productos que directa o indirectamente dañen los ecosistemas (plásticos de un solo uso, pesticidas, alimentos procesados altos en productos o derivados cárnicos, etc.). Esas prácticas no sustentables nos están llevando rápidamente al agotamiento de los suelos y de los cuerpos de agua y con ello comprometiendo seriamente la vida futura. El proyecto Climántica es una herramienta extraordinaria para que en las escuelas podamos fomentar nuevos caminos de vida personal, social y profesional a través de la integración de múltiples recursos y la difusión constante de avances y logros que estimulen la participación ciudadana a todos los niveles. En el Colegio Madrid contamos con ella para el crecimiento sustentable de nuestra comunidad.

6 http://elcambioclimaticodefrente.inecc.gob.mx 